\title{
Pinching the Poor? Medicaid Cost Sharing under the ACA
}

\section{Citation}

Saloner, Brendan, Lindsay Sabik, and Benjamin D. Sommers. 2014. "Pinching the Poor? Medicaid Cost Sharing Under the ACA." N Engl J Med 370 (13) (March 27): 1177-1180. doi:10.1056/nejmp1316370.

\section{Published Version}

doi:10.1056/NEJMp1316370

\section{Permanent link}

http://nrs.harvard.edu/urn-3:HUL.InstRepos:14008380

\section{Terms of Use}

This article was downloaded from Harvard University's DASH repository, and is made available under the terms and conditions applicable to Other Posted Material, as set forth at http:// nrs.harvard.edu/urn-3:HUL.InstRepos:dash.current.terms-of-use\#LAA

\section{Share Your Story}

The Harvard community has made this article openly available.

Please share how this access benefits you. Submit a story.

\section{Accessibility}



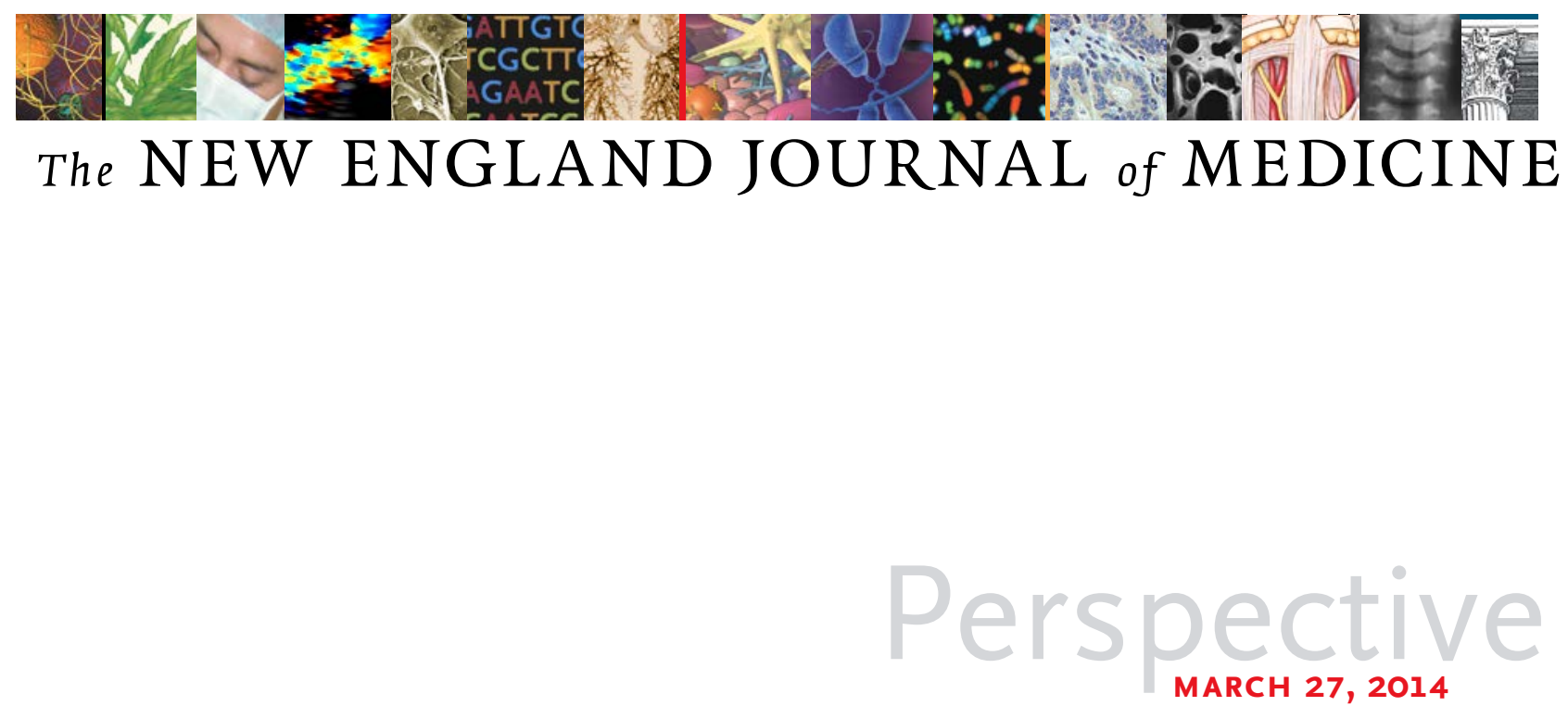

\section{Pinching the Poor? Medicaid Cost Sharing under the ACA}

Brendan Saloner, Ph.D., Lindsay Sabik, Ph.D., and Benjamin D. Sommers, M.D., Ph.D.

\section{n December 12, 2013, the Centers for Medicare and Medicaid Services (CMS) reached an agree- ment with the state of Iowa to expand Medicaid to low-income adults under the Affordable Care Act}

(ACA). The Iowa Medicaid expansion is notable for its far-reaching use of cost sharing, including copayments and monthly contributions for many enrollees. It exemplifies a growing trend in Medicaid - one that raises important questions about balancing state budgetary concerns and appropriate incentives with adequate protections for patients.

In addition to Iowa, last year Arizona, Arkansas, and Michigan pursued Medicaid expansions that involve substantial cost sharing for low-income adults (see table). Michigan and Iowa proposed collecting monthly contributions that enrollees could earn back by engaging in healthy behaviors such as smoking cessation and obesity reduction. Several states that are not currently expanding their Medicaid programs - including Indiana, Tennessee, and Pennsylvania - have developed proposals that also include substantial cost sharing and financial incentives for enrollees.

This policy approach represents largely uncharted territory for Medicaid. For most of the program's history, states could require only "nominal" enrollee contributions, and most required copayments only for services such as prescription drugs (which Medicaid was not required to cover before the ACA). Although the 2005 Deficit Reduction Act per- mitted states to charge Medicaid enrollees up to $5 \%$ of their annual income in cost sharing, most states used these tools only when expanding coverage to higher-income enrollees, and certain groups were exempted from cost-sharing requirements. Meanwhile, monthly premiums and copayments for physician visits (nearly universal in private insurance plans) have been essentially nonexistent for traditional Medicaid beneficiaries - disabled adults, pregnant women, and parents and children with family incomes below the poverty line.

The current move toward cost sharing is partially a consequence of the 2012 Supreme Court decision that rendered Medicaid expansion optional for states. Although roughly half the states have thus far refused to expand their programs, others have seen expansion as an opportunity to 


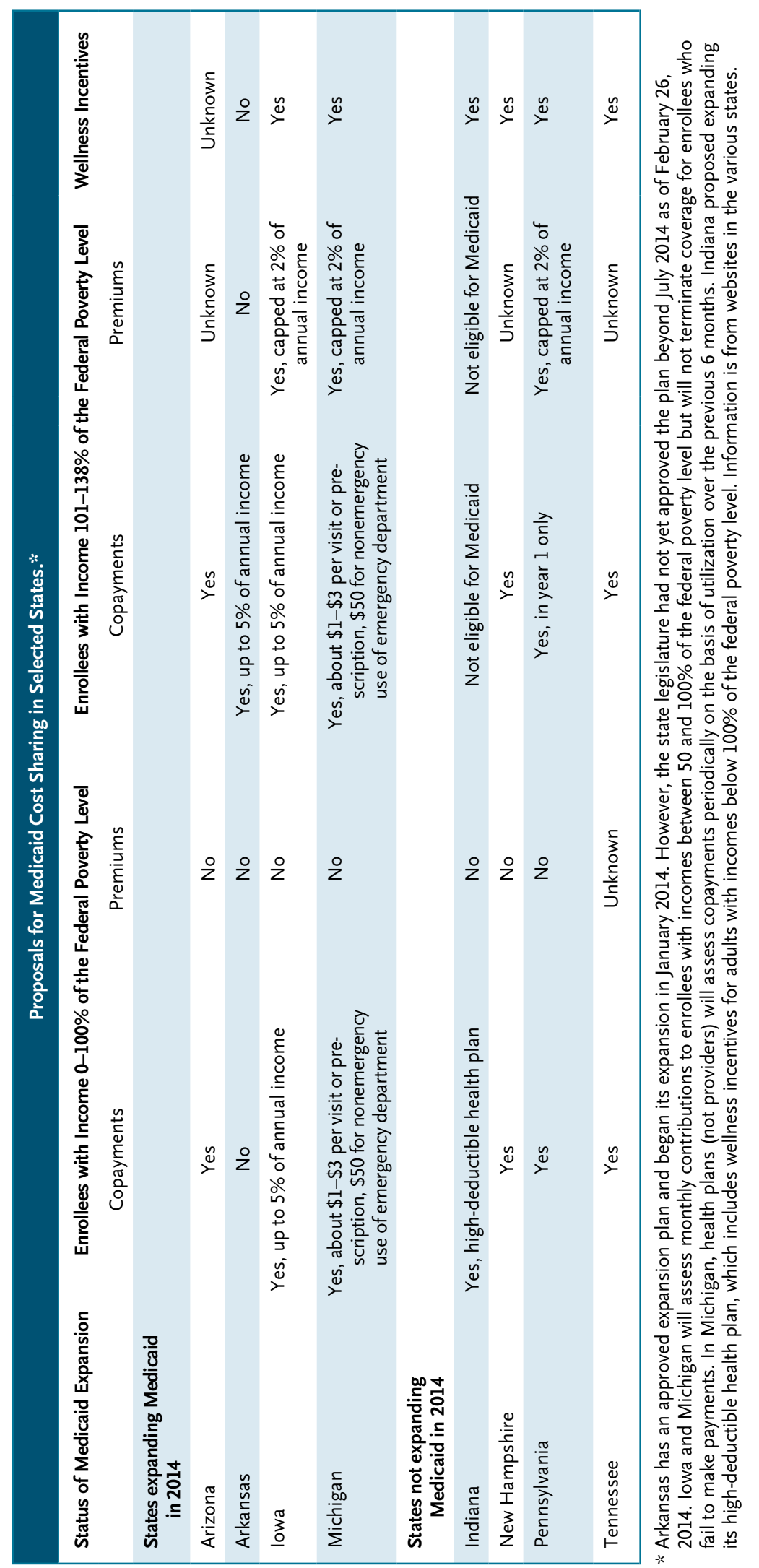

negotiate with CMS for new authority to shift more financial responsibility to enrollees.

In any insurance plan, one objective of cost sharing is to increase efficiency and reduce total spending. Absent cost sharing, enrollees have no incentive to consider cost in making decisions about whether and where to seek care, or what services to receive. Proponents of cost sharing argue that it will lead enrollees to make more efficient health care choices - choosing a generic drug instead of a brand-name drug or waiting to see the doctor instead of visiting the emergency room for a nonurgent problem.

A second objective is to foster personal responsibility. In the words of Iowa Governor Terry Branstad, cost sharing helps enrollees "take ownership of their own health." This notion blends two ideals. One ideal, rooted in libertarian philosophy, is reducing dependence on government services and encouraging financial self-sufficiency. A second, more paternalistic, ideal is helping enrollees make better decisions about their health - choices they might not make without financial incentives.

Beneath the rhetoric, questions remain about whether more cost sharing in Medicaid is desirable policy. Cost sharing could represent a substantial financial burden for people living near the poverty level. A no-frills monthly budget for a single adult with a child in most parts of the United States has been estimated to be more than $\$ 1,300$ : $\$ 300$ for food, $\$ 600$ for rent, $\$ 400$ for transportation, and potentially more for child care and taxes. ${ }^{1}$ On an income of $\$ 1,300$ a month, a family of two (living just above the federal poverty line) may not 
have the resources to afford a $\$ 30$ monthly Medicaid premium, as plans in Michigan and Iowa could require. With multiple prescriptions and provider visits, such a family could easily incur an additional $\$ 20$ per month in costs under some state proposals.

How will these policies affect health care? Substantial evidence suggests that cost sharing at the point of care reduces utilization and spending. The 1970s RAND Health Insurance Experiment (a randomized, controlled trial of alternative insurance designs) showed that cost sharing could reduce spending significantly, with little impact on most measures of health for the general population. However, low-income patients had some adverse effects, particularly in relation to chronic disease management. ${ }^{2}$

More generally, research shows that patients are not good at distinguishing between care that is necessary and care that is not, with the result that cost sharing leads to reduced use of preventive services and essential drugs. ${ }^{3}$ Furthermore, if cost sharing is not well targeted, it may lead to long-run increases in spending. For example, increased cost sharing for medications has been associated with higher utilization of inpatient and emergency department services among patients with chronic illness. ${ }^{4}$ These risks are somewhat mitigated by the ACA requirement that recommended preventive services be covered with zero cost sharing. Nonetheless, concerns remain, particularly since ongoing care for chronic diseases is not considered a preventive service.

Monthly premiums can also have negative consequences. Unlike copayments, premiums create no new incentives for efficient care once someone is enrolled in coverage. But premiums for Medicaid do - intentionally or unintentionally - reduce enrollment. ${ }^{5}$ And the total share of insurance costs covered by proposed premiums will probably be quite small, limiting the revenue that states will collect. Thus, premiums may save states money, but primarily by keeping people uninsured, thereby working against the ACA's primary goal of expanding insurance coverage.

Cost sharing could also create tensions for health care organizations that serve Medicaid patients. Rather than denying treatment to people who are unable to pay, safety-net providers may forgo the copayments, reducing their overall compensation and eroding the resources they have available for caring for uninsured populations and providing important nonreimbursed services such as care coordination.

Nonetheless, political considerations suggest that cost sharing in Medicaid is likely to become increasingly important, since it has proved to be effective at mollifying ideological opposition to program expansion. In this context, we suggest several refinements to increase the likelihood that cost sharing will lead to better outcomes.

Following principles of valuebased insurance design, Medicaid programs could selectively modify copayments to align prices with expected health benefits for example, eliminating copayments on very effective, low-cost drugs such as generic statins and beta-blockers. Similarly, exemptions from copayments could be considered for primary care visits for adults with chronic diseases. Using modest enrollee contributions to encourage health-pro- moting behaviors could be a reasonable approach if Medicaid programs also provided enrollees with the support services that might be needed to enable those behaviors, such as health coaches, smoking-cessation services, and nutritional counseling. In all these cases, clinician input into the design of appropriate incentives with adequate patient protections - would be critical.

Generally, cost sharing is most likely to succeed in cases in which enrollees are able to make informed choices and when financial burdens serve a clear health-related objective. Highdeductible health plans, barriers to emergency care, and premiums without incentives rarely meet these criteria. In CMS's negotiations with Iowa, in which CMS rejected the idea of requiring premiums from people with incomes below the poverty level, the Obama administration acknowledged the inherent balancing act between encouraging innovation and limiting the burden on beneficiaries.

Some state experimentation is undoubtedly worthwhile, but only if it's coupled with rigorous evaluation. Cost sharing is a complicated policy tool. Policymakers have a responsibility to monitor new programs to understand their impact on costs, quality, access, and health and to use the knowledge that is gained to more effectively support the ability of Medicaid enrollees to make good decisions regarding health care. Ultimately, if this sort of flexibility encourages more states to expand Medicaid, most low-income adults will be better off for the effort - since some cost sharing is almost certainly preferable to being left without any coverage at all. 
Disclosure forms provided by the authors are available with the full text of this article at NEJM.org.

From the Robert Wood Johnson Foundation Health and Society Scholars Program, University of Pennsylvania, Philadelphia (B.S.); the Department of Healthcare Policy and Research, Virginia Commonwealth University, Richmond (L.S.); and the Department of Health Policy and Management, Harvard School of Public Health, Boston (B.D.S.).
1. Gould E, Wething H, Sabadish N, Finio N. What families need to get by: the 2013 update of EPI's budget calculator. Issue brief no. 368. Washington, DC: Economic Policy Institute, July 3, 2013.

2. Manning WG, Newhouse JP, Duan N Keeler EB, Leibowitz A, Marquis MS. Health insurance and the demand for medical care: evidence from a randomized experiment. Am Econ Rev 1987;77:251-77.

3. Remler DK, Greene J. Cost-sharing: a blunt instrument. Annu Rev Public Health 2009; 30:293-311.
4. Goldman DP, Joyce GF, Zheng Y. Prescription drug cost sharing: associations with medication and medical utilization and spending and health. JAMA 2007;298:61-9. 5. Wright BJ, Carlson MJ, Allen $\mathrm{H}$, Holmgren $\mathrm{AL}$, Rustvold DL. Raising premiums and other costs for Oregon health plan enrollees drove many to drop out. Health Aff (Millwood) 2010;29:2311-6.

DOI: 10.1056/NEJMp1316370

Copyright (๑) 2014 Massachusetts Medical Society.

\title{
Diagnosing Depression in Older Adults in Primary Care
}

\author{
Ramin Mojtabai, M.D., Ph.D., M.P.H.
}

T he prevalence of diagnosed depression in U.S. adults 65 years of age or older doubled from 3\% to $6 \%$ between 1992 and 2005. ${ }^{1}$ A majority of patients with diagnosed depression were treated with antidepressant medications by primary care and other general medical clinicians. ${ }^{1}$ Several factors probably contributed to this trend, including publicity regarding the extent of underdiagnosis and undertreatment of depression in older adults, aggressive pharmaceutical marketing efforts targeting providers and consumers, and the introduction of new antidepressants. A majority of the people diagnosed with depression in primary care settings, however, do not meet the diagnostic criteria for major depressive disorder. ${ }^{2}$

This conclusion is supported by data from two sets of national surveys conducted between 2005 and 2010 examining the prevalence of major depressive episodes (as defined by the Diagnostic and Statistical Manual of Mental Disorders, fourth edition [DSMIV]) at any time in the previous year, clinicians' diagnoses of depression in the previous year, and current use of antidepressants (see graphs). Like other epidemiologic studies, these data indicate that depression is significantly less prevalent among older adults than in other age groups. The number of antidepressant prescriptions, however, does not match this trend. Although antidepressants are prescribed for various diagnoses, research indicates that almost two thirds of prescriptions are for a clinician-diagnosed mood disorder. The correspondence between clinicians' diagnoses and diagnoses based on structured interviews is significantly poorer in older adults than in younger adults (see graph, Panel B). Only $18 \%$ of older adults with a clinician's diagnosis of depression meet the diagnostic criteria for a major depressive episode on the basis of a structured interview. Clinical studies have similarly shown that less than one third of older adults with major depression diagnosed by primary care clinicians also meet the diagnosis of major depression according to structured interviews or rating scales. ${ }^{3}$

It's difficult to diagnose depression in primary care set- tings, especially in older adults. Sleep problems, fatigue, and low energy levels associated with medical conditions often mimic depressive symptoms. Furthermore, losses of friends and loved ones and a shrinking social network in old age result in diminished social involvement, which is a common feature of depression. These problems of old age are sometimes difficult to distinguish from depressive symptoms.

The challenge of correctly identifying depression in primary care is compounded by the fact that depressed patients seen in these settings have less-clear-cut symptom profiles than those seen in specialty mental health settings, mainly because their symptoms are less severe or disabling. Some patients diagnosed with depression in primary care may meet the criteria for dysthymia or adjustment disorder with mood symptoms. Others may have mild depressive symptoms that don't reach the threshold for diagnosis of major depressive disorder. Many such patients would benefit from supportive counseling or lifestyle modification. In some cases, watchful 